\title{
DIET DEFICIENCY AND TRACHOMA
}

To the Editors of The British Journal of Ophthalmology.

Sirs.-In his letter to the Medical Journal of Australia published in the issue of October 10, to which attention was drawn in the current number of the British Journal of Ophthalmology, Dr. Lockhart Gibson refers with kindness to a paper of mine on the Epidemioloy of Trachoma (Brit. Jl. of Ophthal., July, 1931.) He comments on the absence of mention of a deficiency of vitamin A in the diet as a contributory agent in the causation of trachoma.

It is usually accepted that any depressed physical condition presents a more favourable culture medium for the infective principle of contagious disease than perfect health. It may be conceded, therefore, that this may be the case with trachomatous infiltration of the eye and its appendages. But trachoma is constantly being seen in children who have enjoyed the rich and varied diet which is common in the homes of well-to-do fellahin in Egypt, as well as in the homes of Europeans, and who are apparently in admirable physical condition.

In exceptionally severe cases of trachoma, which may be met with in stages $\operatorname{Tr}$. II $a$ and $\operatorname{Tr}$. II $b$, it is common to find a severely depressed physical condition due to famine, ankylostomiasis, bilharziasis, or all these conditions combined.

I must, therefore, state that as far as my experience goes neither - defective diet, nor a depressed physical condition (including the so-called adenoidism) is an essential factor in the process of trachomatous infection.

Dr. Lockhart Gibson is not quite correct in stating that primary infection with trachoma was unknown in Egypt during the War. Colonel Eason, A.M.S., reported that in two and a half years between 1916 and 1918 out of 30,000 eye cases among the troops he found 63. men to have contracted trachoma in Egypt or Palestine (Bulletin of the Ophthalmological Society of Egypt, 1919).

I agree with Dr. Lockhart Gibson that there is no reason why a patient with certain of the less virulent stages of trachoma, such as Tr. III, should not occupy a bed in the general ward of a hospital provided that (1) ordinary hospital regulations are observed, including a special towel for each patient; (2) the ward is staffed by adequately trained nurses; (3) flies are excluded from the ward or are present sparsely ; (4) neither the trachoma patient nor the other patients in the ward have any definite conjunctival discharge.

In the last paragraph of the editorial note in the British Journal 
of Ophthalmology, January, 1932, it is suggested that an experimental study on the question of diet as an essential factor in infection with trachoma would not present insuperable difficulties. Unfortunately it has not been conclusively proved that any living creature, other than man, can either naturally or by inoculation be made to exhibit those clinical signs by which the disease is recognized.

Yours faithfully,

January 6, 1932.

A. F. MacCallan.

\section{NOTES}

Death

WE learn, with regret, of the death of Dr. further particulars in a later issue.

George S. Derby, of Boston, and hope to give

Royal London THE Annual Dinner of the Royal London

Ophthalmic Hospital. Ophthalmic Hospital (Moorfields) will take

Annual Dinner place on Thursday, February 11, 1932. The

Chairman will be Sir William Lister, K.C.M.G.

Ophthalmological

Society of the United

Kingdom.

Annual Congress

THE discussion on the pre- and post-operative complications of cataract will be opened by Dr. A. J. Ballantyne. Sir Arnold Lawson and Mr. Bernard Cridland will take part in the discussion.

The Campaign against $T$ rachoma
THE executive committee of the International Organization of the Campaign against Trachoma (founded in 1929 in connection with the Amsterdam International Ophthalmological Congress) elected in Geneva in 1930, assembled on November 13, 1931, in Paris, under the presidency of Dr. Emil v. Grósz. Members present were, besides the general secretary, F. Wibaut: A. Angelucci (Naples), A. F. MacCallan, M.D. (London), M. Marquez (Madrid), V. Morax, M.D. (Paris), Park Lewis, M.D. (Buffalo), - Brandès, M.D. (Antwerp), F. de Lapersonne (Paris), J. van der Hoeve (Leyden), -- Zachert (representing Prof. Szymanski, Wilno), and finally, as a representative of the Hygienic Section of the League of Nations, Dr. Pantaleoni.

In his opening speech the president intimated that twenty-four manuscripts had been received for the International TrachomaPrize-fight instituted by the Royal Hungarian Government. The preparations for this Assembly were made by the general secretary, 